\title{
Fatty change in the brain in perinatal and unexpected death
}

\author{
D. R. GADSDON and JOHN L. EMERY \\ From the Department of Histopathology, Children's Hospital, Sheffield
}

\begin{abstract}
Gadsdon, D. R., and Emery, J. L. (1976). Archives of Disease in Childhood, 51, 42. Fatty change in the brain in perinatal and unexpected death. The presence of fat-laden cells in the cerebrospinal fluid is usually associated with a fatty change found particularly in the area of the tapetum in the postnatal infant. In a series of 307 child deaths the presence of fatty change in this area of the brain was age-related, decreased with age, and was rarely present over the age of 4 years. It was particularly common in stillborns and in children dying with respiratory distress, but was rare in children dying from acute surgical conditions or from acute infections.

It was found in one-half of a series of 41 infants found unexpectedly dead and in whom no adequate cause of death was found. The most likely cause of this fatty change is thought to be chronic hypoxia.
\end{abstract}

While carrying out routine examinations of the cerebrospinal fluid (CSF) of children under treatment for hydrocephalus we were impressed by the presence of many large fat-laden cells (Fig. 1). These cells were usually associated with areas of necrosis in the distended cerebral hemisphere, and the presence of large numbers of these

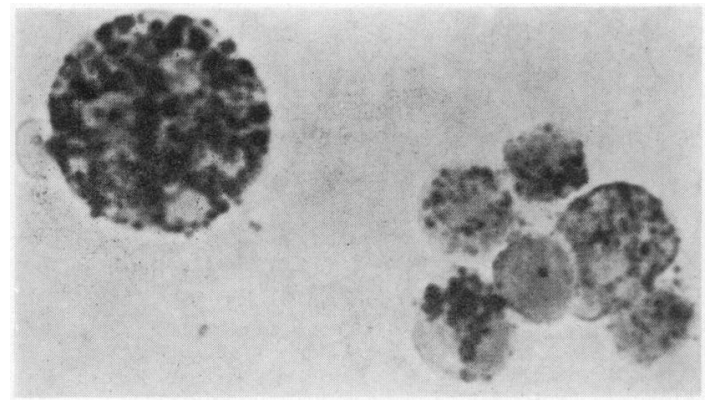

FIG. 1.-Centrifuged deposit from CSF, showing a large fat-laden cell and several smaller cells containing varying numbers of fat droplets. (Sudan IV. $\times 1150$.

fat-laden cells in the CSF was associated with a bad prognosis (Chester, Emery, and Penny, 1971). Since that time the examination of CSF for such cells has become one of our routine laboratory procedures.

Received 21 April 1975.
It soon became clear that many specimens of CSF from children who had no overt brain disease contained many fat-laden cells, and this applied in some children in whom no obvious cerebral pathology was seen on routine histology. Thus a twostage study was carried out, first to identify the apparent site of origin of the fat-laden cells, and second to attempt an estimate of their significance.

\section{Material and method}

CSF was examined as part of routine necropsy procedure by puncturing the arachnoid over the fourth ventricle just below the foramen magnum. Centrifuged deposits were stained with Sudan IV (Chester et al., 1971), and the number of fat-laden cells expressed as a percentage of the nucleated cells seen.

Preliminary study of sites of origin of cells. A series of brains and spinal cords were taken from children having no gross anatomical deformity of the brain. These comprised 15 children having a fat-laden cell count ranging from $5-83 \%$, and 10 children with negative fat-laden cell counts. The 15 'positive' cases included 3 with bacterial meningitis, 3 with respiratory distress syndrome, 4 stillbirths, and 5 who presented as unexpected death in infancy. The 10 'negative' cases were of children of the same ages as the 'positive' group, and dying from a similar range of diseases.

The brains and spinal cord were fixed in $10 \%$ formol calcium (Baker, 1949). Blocks taken included most segments of the spinal cord, the brain stem, the posterior, anterior, and inferior horns of the lateral ventricles, the 
corpus callosum, septum pellucidum, the fornix and choroid plexus, the cerebellum, the surfaces of the 4th ventricle, and meninges. Frozen sections were prepared and were stained for lipids by the oil red $\mathrm{O} /$ triethylorthophosphate method (Gomori, 1952) and counterstained with alum haematoxylin. Duplicate blocks were processed through paraffin wax for routine histology.

Definitive survey. This was a sequential series of children coming to necropsy, comprising 200 children dying in hospital from a variety of diseases, and 107 children examined through the office of the Coroner as unexpected death in infancy (UDI). As part of the routine necropsy procedure, after fixation a standard block was taken from the lateral aspect of the corpus callosum in the area shown in Fig. 2.

These blocks were all processed, handled, and assessed by one of us who was not concerned with the necropsy and the routine histology of the case, and it was only after assessment of the lipid changes in the brain had been made that the results were $e_{j}$ correlated with the CSF and necropsy findings.

\section{Results}

Sites of fat-laden cells in the brain. In virtually all blocks investigated there were isolated fat-containing cells (Fig. 3). These cells were usually in contact with a small blood vessel (presumably the so-called perithelial cell). There was a group of large fat-containing cells at the upper end of the cavity of the septum pellucidum and isolated fat-laden cells or isolated fat droplets were seen among the myelinating tracts in many parts of the brain. Thus a minimal scatter of fat-laden cells and fat droplets was invariable in children dying in the perinatal period but became increasingly scarce in older children. After the age of 8 months such cells were rarely seen. These isolated cells were seen in children who did not show fat-laden cells in the CSF.

In the group with the raised CSF fat-laden cell count most cases showed large numbers of fat-laden cells in the brain tissue. All showed the same basic distribution pattern. The areas involved were related to the corpus callosum and the lateral ventricles, particularly among the fibres of the corpus callosum and its radiations into the lateral hemispheres. The fat droplets occurred in diffuse clusters, both intra- and extracellularly, and frequently formed thick coats around capillaries (Fig. 4). Paraffin sections showed in some brains in these same areas some perivascular vacuolation which previously we had discarded as being a technical artefact (Fig. 5). There were also large numbers of fat-laden cells in the subependymal zone of the lateral ventricle, and such cells were apparently entering the lateral ventricles through tears or gaps in the ependyma. A large number of fat-laden cells occupied the septum pellucidum and the fornix. The number of such cells in the leptomeninges varied, by far the highest number

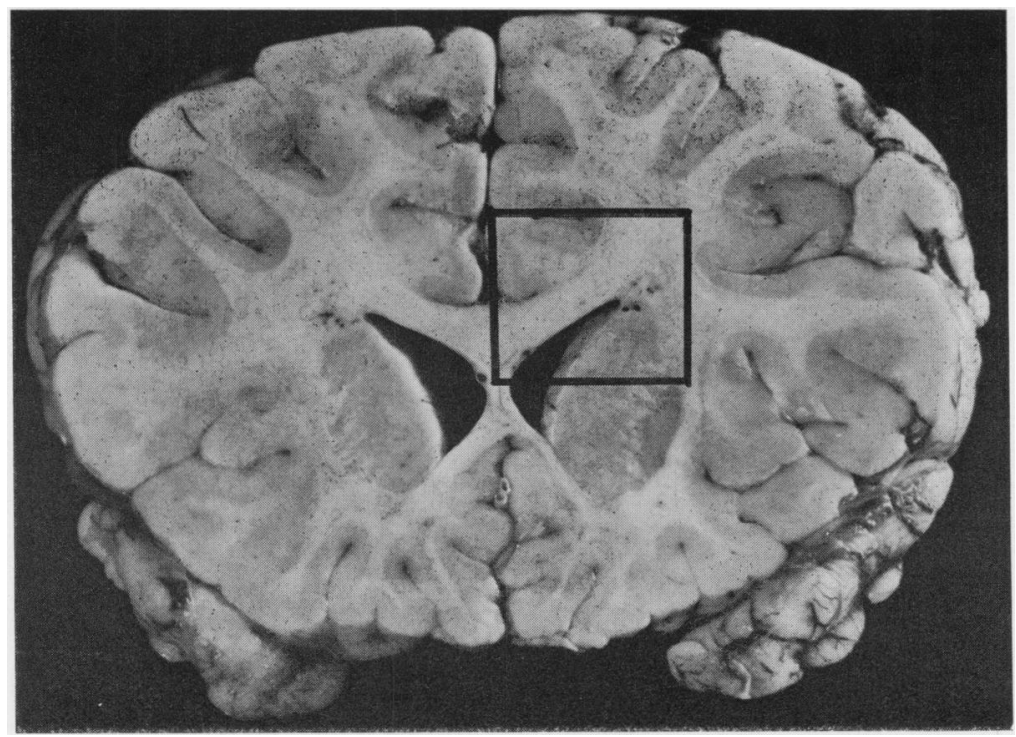

FIG. 2.-Coronal slice across both hemispheres of the brain. The area within the box, including the corpus callosum, septum pellucidum, and part of the caudate nucleus, was that selected for the definitive study. 


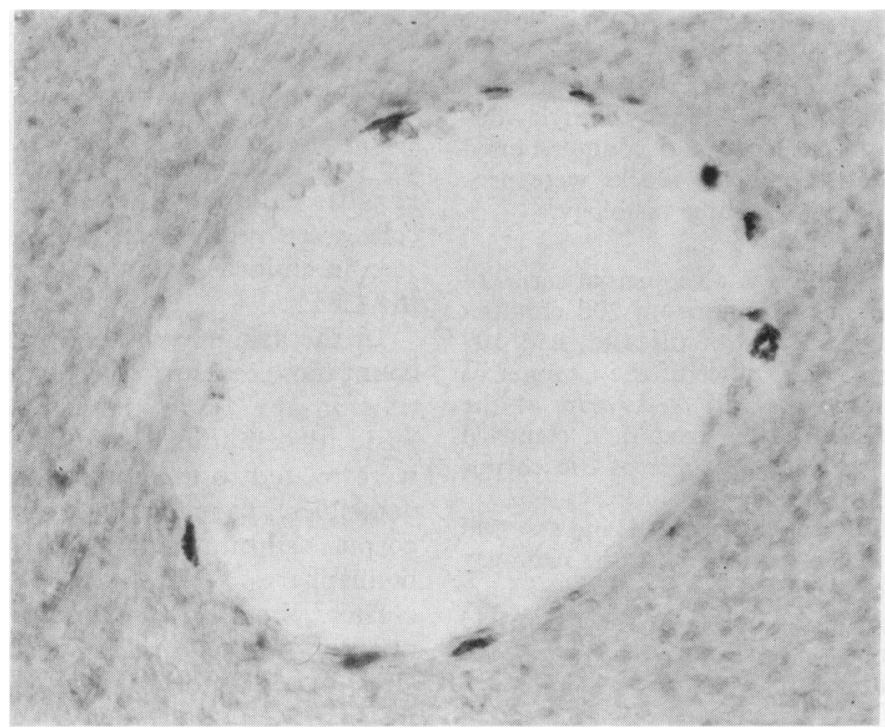

FIG. 3.-Frozen section of corpus callosum. A small number of fat-containing cells in intimate contact with a small blood vessel. Fat stains red. Photograph taken with green filter which shows the fat as black. (Oil red O/triethylorthophosphate. $\times$ 270.)

appeared in the brain tissue just deep to the meninges, in the 2 cases with meningitis. While occasional fat-laden cells were present in the pons, medulla, and spinal cord, we found no clustering and extensive areas of change as seen in the corpus callosum. It appeared that in these infants the majority of fat-laden cells seem to arise from the areas of the brain associated with the corpus callo-

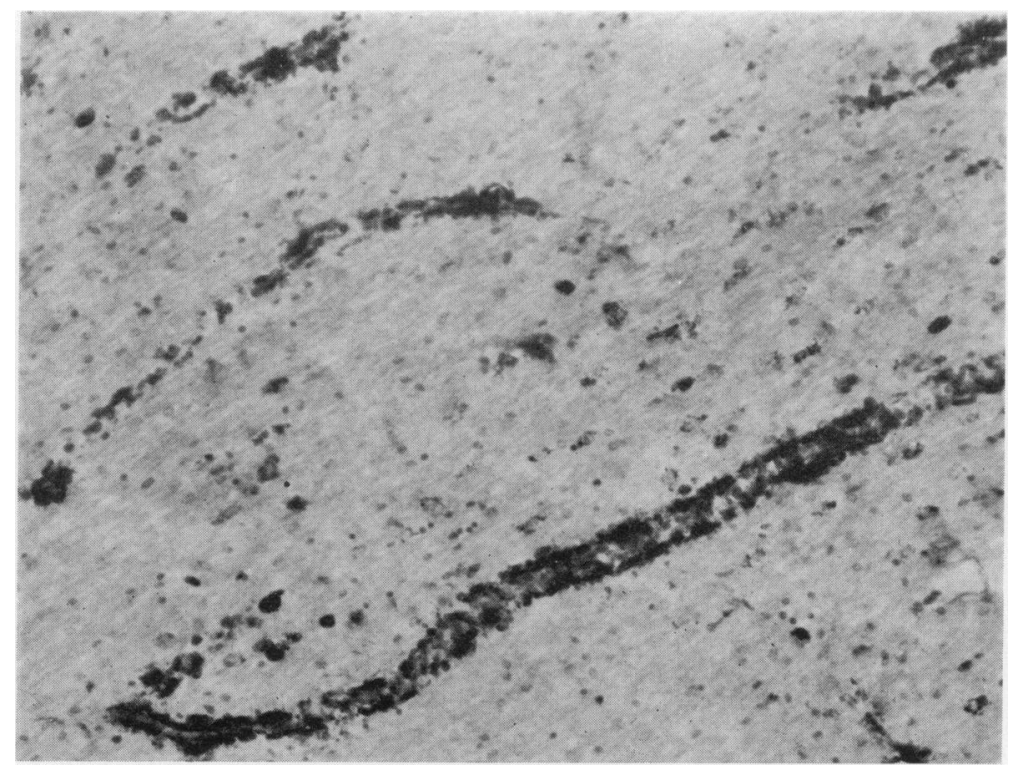

FIG. 4.-Frozen section of corpus callosum. Abnormal numbers of free fat-laden cells associated with a coating of lipid material (both intra- and extracellular) around capillaries. (Oil red O/triethylorthophosphate. $\times 100$.) 


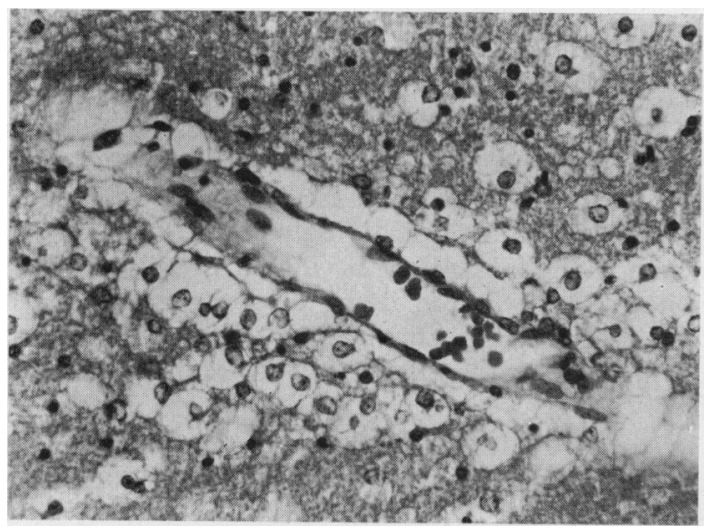

FIG. 5.-Paraffin section of corpus callosum from the same case as Fig. 4. Large numbers of vacuolated cells associated with a capillary. Fat unstained shows as clear spaces. (H. and $E . \times 227$.)

sum and a few enter the CSF through the ependyma of the lateral ventricles in these areas. Only a relatively small proportion of fat-laden cell interchange seemed to occur with the CSF; the principal exchange appears to be between the cerebral tissue and the cerebral blood vessels. For this reason the standard block was selected for the routine study in the area of the tapetum as shown in Fig. 2.

From these results two categories of children were defined, the 'negative' cases where only the occasional fat-laden cell and a few lipid droplets were seen, and the cases showing what we call 'fatty change', that is with large numbers of fatladen cells present with or without capillary involvement (Figs. 4 and 6).

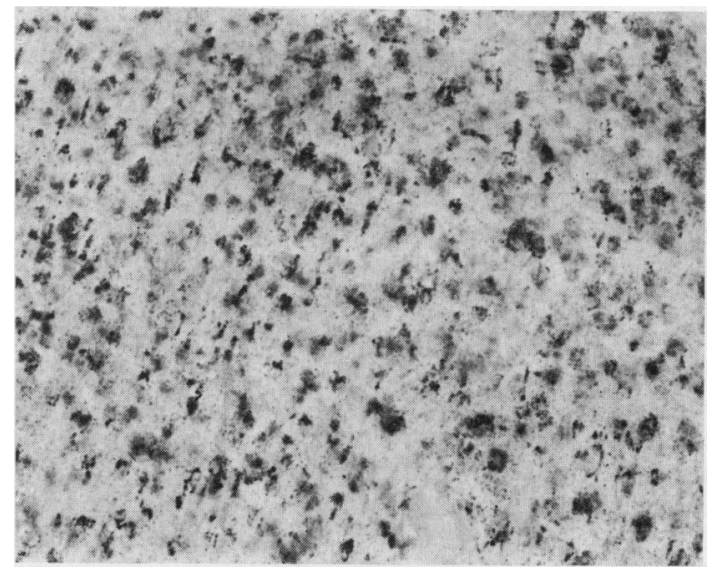

Fig. 6.-Frozen section of corpus callosum. Numerous large fat-laden cells lying among the myelinating tracts. (Oil red O/triethylorthophosphate. $\times 132$.)

A. Hospital deaths. The number of children dying in particular disease groups together with the number showing fatty change in the brain is shown in Table I. Overall, $58(29 \%)$ of the children's brains showed fatty change. The highest incidence was found in stillborns and in children with the respiratory distress syndrome. Of the 23 stillbirths 19 presented with evidence of considerable chronic hypoxia and 4 showed changes of traumatic delivery. 8 of the 11 children with hydrocephalus and spina bifida in this series showed fatty change and among these children the negative cases were all older children.

The congenital heart disease group showed an incidence of $45 \%$, the negative cases tending to be

TABLE I

Incidence of fatty change in brains of children appearing as hospital deaths

\begin{tabular}{|c|c|c|c|}
\hline Disease classification & $\begin{array}{l}\text { Total no. } \\
\text { of cases }\end{array}$ & $\begin{array}{c}\text { No. of cases } \\
\text { with fatty change }\end{array}$ & $\%$ \\
\hline $\begin{array}{l}\text { Spina bifida and hydrocephalus } \\
\text { Neoplasms } \\
\text { Pyelonephritis, septicaemia, gastroenteritis, } \\
\text { and tracheobronchitis } \\
\text { Meningitis (bacterial and viral) } \\
\text { Respiratory distress syndrome } \\
\text { Exomphalos and microcephaly } \\
\text { Hepatic failure } \\
\text { Stillbirths } \\
\text { Meconium ileus with peritonitis } \\
\text { Cystic fibrosis } \\
\text { Congenital heart disease } \\
\text { Pulmonary oedema and cerebral haemorrhage } \\
\text { Intrauterine pneumonia }\end{array}$ & $\begin{array}{r}11 \\
22 \\
41 \\
11 \\
14 \\
13 \\
10 \\
23 \\
15 \\
5 \\
22 \\
12 \\
1\end{array}$ & $\begin{array}{r}8 \\
1 \\
0 \\
4 \\
12 \\
0 \\
0 \\
20 \\
0 \\
0 \\
10 \\
2 \\
1\end{array}$ & $\begin{array}{r}73 \\
4 \\
0 \\
36 \\
87 \\
0 \\
86 \\
0 \\
45 \\
17\end{array}$ \\
\hline Total & 200 & 58 & 29 \\
\hline
\end{tabular}


in the older children, often dying during cardiac surgery. Only 4 of the children with meningitis showed fatty change deep in the brain, though the majority showed some fat-laden cells in the leptomeninges.

The neoplasia group included leukaemias, lymphomas, teratomas, neuroblastomas, nephroblastomas, and a meningioma, but the only child showing fatty change was one with a malignant sacrococcygeal teratoma who had extensive intracerebral secondaries. In the group of 41 children dying with acute infections no fatty change was seen, nor in 10 dying of hepatic failure. No changes were found in 15 dying with meconium ileus and peritonitis, or 5 with cystic fibrosis of the pancreas. There appears, thus, to be a disease group relation in the incidence of the fatty change.

There is also a definite age relation in the proportion of children showing fatty change. Table II shows the proportion of children dying at different age groups and includes all of the hospital death groups mentioned in Table I and also the 107 children dying unexpectedly.

B. Unexpected death in infancy (UDI). It is the practice in this department to subdivide children found unexpectedly dead into four major groups (Emery, Swift, and Worthy, 1974). Groups $A$ and $B$ are essentially explained deaths, and groups $\mathrm{C}$ and $\mathrm{D}$ inadequately explained deaths. The proportion of children falling into these groups together with the incidence of each group showing fatty change is shown in Table III. The overall incidence was $41 \%$. Exactly half of the 42 children falling into the $\mathrm{C}+\mathrm{D}$ category, i.e. the least well explained deaths, showed fatty change. Group B included many children dying with acute infections, which is not surprising in view of the finding that none of the children dying of acute infections in hospital show fatty change, that this is the group of unexpected deaths showing the lowest proportion of fatty change.

Group $\mathrm{A}$ is the smallest group and contained a mixed profile of congenital deformities or longstanding disease, including children with congenital heart disease, all of whom showed fatty change.

The relation of the findings in the standard brain block to the proportion of fat-laden cells found in the CSF is shown in Table IV. The finding of fatty change in the brain shows a direct correlation with the number of children showing fat-laden cells in the CSF. Only 19 of the 205 children in whom no fatty change was found in the brain showed fat-laden cells in the CSF. On the other hand, 98 of the 102 children showing fatty change in the brain showed fat-laden cells in the CSF.

The presence of a few children with some fatladen cells in the CSF but with no fatty change in

TABLE II

Number of hospital death cases and unexplained deaths in infancy (UDI) showing fatty change compared with the total number in different age groups

\begin{tabular}{|c|c|c|c|c|c|c|}
\hline \multirow{2}{*}{ Age } & \multicolumn{3}{|c|}{ Hospital deaths } & \multicolumn{3}{|c|}{ UDI } \\
\hline & Total no. of cases & Fatty change & $\%$ & Total no. of cases & Fatty change & $\%$ \\
\hline
\end{tabular}

TABLE III

Incidence of fatty change in brains of children dying as unexplained deaths in infancy (UDI)

\begin{tabular}{c|c|c|c}
\hline UDI classification & Total no. of cases & No. of cases with fatty change & $\%$ \\
\hline A & 16 & 8 & 50 \\
B & 49 & 15 & 31 \\
(C +D) & 42 & 21 & 50 \\
\hline Total & 107 & 44 & 40 \\
\hline
\end{tabular}


TABLE IV

Correlation of fatty change and percentage of fat-laden macrophages in CSF in both the hospital death cases and the UDI groups

\begin{tabular}{|c|c|c|c|c|c|}
\hline & \multirow[t]{2}{*}{ No. of cases } & \multicolumn{4}{|c|}{ No. of cases showing the percentage of fat-laden cells in the CSF } \\
\hline & & $0-5 \%$ & $5-10 \%$ & $10-30 \%$ & $30+\%$ \\
\hline $\begin{array}{l}\text { Cases showing fatty } \\
\text { change } \\
\text { Cases showing no } \\
\text { evidence of fatty } \\
\text { change }\end{array}$ & $\begin{array}{l}102 \\
205\end{array}$ & 14 & $\begin{array}{r}13 \\
1\end{array}$ & 48 & 31 \\
\hline
\end{tabular}

our brain block is not surprising, in view of the fact that we only took one standard block from the brain; however only $2 \cdot 4 \%$ of these cases had a fatladen cell count of over 5\%. Expressed in a somewhat different way, of the 102 children showing fatty change in the brain, $90 \%$ of these had over $5 \%$ fat-laden cells in the CSF.

The relation of the presence of fatty change in the brain to age made it necessary for us to check the age range of the different disease groups for any possible pathological correlation. A group having an almost identical age distribution as the $C+D$ unexpected deaths are the children dying from surgical conditions of the intestine, namely meconium ileus and peritonitis, also exomphalos and cystic fibrosis, and these two distribution curves are shown in Fig. 7. The finding that $50 \%$ of the $\mathrm{C}+\mathrm{D}$ cases show both fat-laden macrophages in the CSF and fatty change in the brain, while the surgical group shows no change, indicates a pathological significance.

\section{Discussion}

The presence of neutral fat droplets in the central nervous system in infants was described by Virchow (1867), who considered it to be due to congenital encephalitis. Others have occasionally observed it,

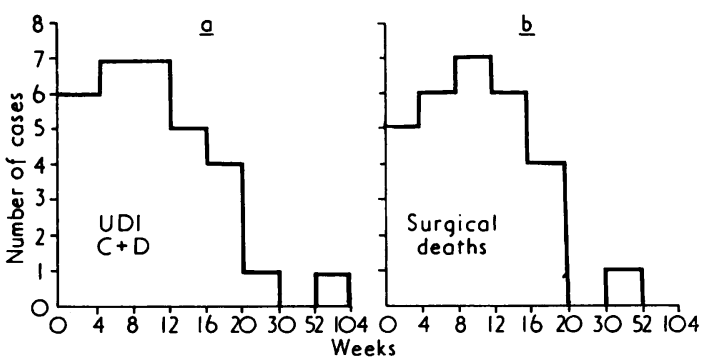

FIG. 7.-Age distribution of two groups of children. (a) Unexplained deaths of infancy, (b) surgical deaths in the hospital which were consequent on intestinal tract disease. The age distribution of both groups is virtually identical, yet $50 \%$ of the UDI group showed fatty change, while none of the surgical group did so. some have thought it to be pathological, and others a phenomenon of normal neural development. Tuthill (1938) and Mickel and Gilles (1970) both agreed that there is some free and intracellular lipid material in parts of the brain including the corpus callosum, and both noted it to be prominent at birth and decreased with age. They found considerable variation in the amount and extent of the free lipid and also in the timing of the appearance and disappearance of this material. Our observations suggest that the occurrence of isolated fat-laden cells in actively myelinating parts of the child's brain are probably normal, but that the presence of larger aggregates and cuffs around capillaries are abnormal. This is substantiated by the finding of isolated lipid cells in all children but that some quite large groups of children dying in the perinatal period do not show gross accumulations of lipid. It is likely that earlier workers have been misled by the misconception, common to most workers until the last few years, that normalappearing stillborn children were essentially normal, and were killed by some aspect of labour, whereas in fact the majority of stillborns and neonatal deaths occur in children who were ill in utero and most of whom have been subjected to hypoxia during and after birth.

There is an obvious link between the well recognized situation of chronic hypoxia inchildren with respiratory distress and in children with congenital heart disease, and thus the fatty change could well be the effect of chronic hypoxia. However, other general metabolic upsets, such as hypernatraemia or hypoglycaemia, could well be imagined to be equally related to the same lesion.

Mickel and Gilles (1968) considered that the child's plasma is physiologically hyperlipaemic, that the blood-brain barrier is not fully developed and enables ready movement of lipid globules through blood vessels into the brain substance. Gröntoft, (1954) showed that even in fetuses a blood-brain barrier exists to trypan blue but is affected by hypoxia which produces increased permeability. 
It seems possible that lipid globules could move through vessel walls in a hypoxic brain.

Another concept is that the fat arises as a result of demyelination of the myelinating tracts, and this lipid is removed by macrophages. Morrison (1946) showed that demyelination of the corpus callosum occurs in mature dogs and monkeys exposed to episodes of hypoxia, and that this demyelination was not associated with gliosis.

Finally, it has been shown that myelination is preceded by multiplication of glial cells in the process of myelination (Bensted et al., 1957; Friede, 1961) and this is referred to as 'myelination gliosis' (Mickel and Gilles, 1970). This premyelination stage has been shown to be be extremely sensitive to hypoxia by Petropoulos, Dalal, and Timiras, (1972).

The exact cytochemical stages involved in myelin formation have not yet been discovered, although we know that the majority of the typical myelin lipids are present before the myelin sheaths are seen (Uzman and Rumley, 1958), and that histochemically the newly formed myelin sheaths are rich in hydrophobic lipids, probably cholesterol esters (Adams and Davison, 1959). We have carried out limited histochemical studies on our material and the results appear to confirm the presence of cholesterol esters in these fatty change lesions. Our results also indicate that there is some difference between the lipid material coating the vessels and in the fat-laden cells observed among the myelinating tracts. It is feasible that injury could manifest itself as an alteration in the metabolism or synthetic capability of the myelinogenetic cells, resulting in accumulations of lipid material in those parts of the central nervous system involved in the key stages of myelin formation at the time of injury. We know from the studies of Langworthy (1933), Larroche (1966), and Yakovlev and Lecours (1967) that the myelination of the corpus callosum starts around the time of birth, and continues for some considerable time, and it is therefore a region of the brain which is most likely to show evidence of damage produced by agents affecting the brain during the immediate postnatal period.

The examination of the CSF for fat-laden cells at necropsy is useful. Within our present series the significant level of fat-laden cells in the CSF deposit is set at over 5\%. If meningitis and hydrocephalus are excluded the prevalence of false positives is very low indeed (less than $0.5 \%$ ).

We feel that the lesions in the brain when found are of pathological and not physiological significance, and in view of the indirect evidence by analogy with groups of children dying from conditions with which hypoxia is strongly related and who showed fatty change, that chronic hypoxia is the most likely cause of the condition. That one-half of the children found unexpectedly dead and in whom no pathology was identified is important. If these lesions are due to hypoxia then this finding supports the suggestions by Naeye (1973) based on changes caused by hypoxia in the pulmonary small arteries in many children found unexpectedly dead. Such lesions do not explain death, they are merely a guide as to probable pathways to death.

\section{REFBRENCES}

Adams, C. W., and Davison, A. N. (1959). The occurence of esterified cholesterol in the developing nervous system. Fournal of Neurochemistry, 4, 282.

Baker, J. R. (1949). Further remarks on the Golgi element. Quarterly fournal of Microscopical Science, 90, 293.

Bensted, J. P. M., Dobbing, J., Morgan, R. S., Reid, R. T. W., and Payling-Wright, G. (1957). Neuroglial development and myelination in the spinal cord of the chick embryo. Fournal of Embryology and Experimental Morphology, 5, 428.

Chester, D. C., Emery, J. L., and Penny, S. R. (1971). Fat-laden macrophages in cerebrospinal fluid as an indication of brain damage in children. Fournal of Clinical Pathology, 24, 753.

Emery, J. L., Swift, P. G. F., and Worthy, E. (1974). Hypernatraemia and uraemia in unexpected death in infancy. Archives of Disease in Childhood, 49, 686.

Friede, R. L. (1961). A histochemical study of DPN-diaphorase in human white matter with some notes on myelination. fournal of Neurochemistry, 8, 17.

Gomori, G. (1952). Microscopic Histochemistry. University Press, Chicago.

Gröntoft, O. (1954). Intracranial haemorrhage and blood-brain barrier problems in the newborn. Acta Pathologica et Microbiologica Scandinavia, Suppl. 100.

Langworthy, O. R. (1933). Development of behavior patterns and myelinization of the nervous system in the human fetus and infant. Contributions to Embryology, 24, 1.

Larroche, J. C. (1966). The development of the central nervous system : during intrauterine life. Human Development, p.257. Ed. by F. Falkner. Saunders, Philadelphia and London.

Mickel, H. S., and Gilles, F. H. (1968). Changes in glial cells during myelogenesis. fournal of Neuropathology and Experimental Neurology, 27, 146.

Mickel, H. S., and Gilles, F. H. (1970), Changes in glial cells during human telencephalic myelinogenesis. Brain, 93, 337.

Morrison, L. R. (1946). Histopathologic effect of anoxia on the central nervous system. Archives of Neurology and Psychiatry, $55,1$.

Naeye, R. L. (1973). Pulmonary arterial abnormalities in the sudden-infant death syndrome. New England fournal of Medicine, 289, 1167.

Petropoulos, E. A., Dalal, K. B., and Timiras, P. S. (1972). Effects of high altitude on myelinogenesis in the brain of the developing rat. American fournal of Physiology, 223, 951.

Tuthill, C. R. (1938). Fat in the infant brain in relation to myelin, blood vessels and glia. Archives of Pathology, 25, 336.

Uzman, L. L., and Rumley, M. K. (1958). Changes in the composition of the developing mouse brain during early myelination, fournal of Neurochemistry, $3,170$.

Virchow, R. (1867). Zur pathologischen Anatomie des Gehirns. I. Congenitale encephalitis und Myelitis. Virchows Archiv für Pathologische Anatomie und Physiologie und für Klinische Medizin, 38, 129.

Yakovlev, P. I., and Lecours, A. (1967). The myelogenetic cycles of regional maturation of the brain. Regional Development of the Brain in Early Life, p. 3. Ed. by Minkowski. Blackwell, Oxford.

Correspondence to Prof. J. L. Emery, Department of Histopathology, Children's Hospital, Western Bank, Sheffield. 